\title{
Using Digital Twining in Fast-food Production Chain Simulation
}

\author{
Florina Chiscop ${ }^{1, *}$, Bogdan Necula ${ }^{1}$, Carmen Cristiana Cazacu ${ }^{1}$ and Cristian Eugen Stoica ${ }^{2}$ \\ ${ }^{1}$ University Politehnica of Bucharest, Robots and Production System Department, 313 Splaiul \\ Indepedentei, Bucharest, Romania \\ ${ }^{2}$ National Research and Development Institute for Gas Turbines COMOTI, 220 D Iuliu Maniu Bd., \\ sector 6, cod 061126, OP 76, CP174, Bucharest, Romania
}

\begin{abstract}
The topic of this paper represents our research in the process of creating a virtual model (digital twin) for a fast-food company production chain starting with the moment when a customer launches an order, following with the processing of that order, until the customer receives it. The model will describe elements that are included in this process such as equipment, human resources and the necessary space that is needed to host this layout. The virtual model created in a simulation platform will be a replicate of a real fast-food company, thus helping us observe the real time dynamic of this production system. Using WITNESS HORIZON 23 we will construct the model of the layout based on real time data received from the fast-food company. This digital twin will be used to manage the production chain material flow, evaluating the performance of the system architecture in various scenarios. In order to obtain a diagnosis of the system's performance we will simulate the workflow running through preliminary architecture in compliance with the real time behaviour to identify the bottlenecks and blockages in the flow trajectory. In the end we will propose two different optimised architectures for the fast-food company production chain.
\end{abstract}

\section{Industry 4.0 impact in fast-food industry}

As structural elements of an Industry 4.0 architecture smart products networks suggest a new design for smart processing and manufacturing architectures [1 - 4]. At the most basic level, equipment development shifts from largely mechanical engineering to true interdisciplinary systems engineering $[5,6]$. Smart, connected products require a whole new supporting technology infrastructure based on IoT power and digital twining [7 - 10]. This "technology stack" provides a gateway for data exchange between the product and the user and integrates data from various sources $[11,12]$.

In this context the fast-food business is not anymore only about the speed \& quality of the products. To keep up with the consumer's demands the technology evolved integrated various elements of the digital era of Industry 4.0 [13 - 15]. In this approach human resources

\footnotetext{
* Corresponding author: florina.chiscop@upb.ro
} 
management will be fundamentally different, based on virtual networks and other Industry 4.0 specific structures $[16,17]$. In fast food industry like in manufacturing some traditional qualifications have changed significantly, their configuration being determined by the emergence of new digital technologies, automation and robotics [18 - 21]. Like in the smart manufacturing paradigm, the artificial intelligence now performs specific tasks in food processing. This article is about taking the fast-food automation process to the next level integrating virtual prototypes acting like an Industry 4.0 digital twin in optimizing processing architectures.

To start with, a state of the arts study was conducted to summarize what currently exists in terms of automation and digital approach in this industry. To do so three of the most relevant examples were chosen as follows:

\subsection{KFC Kiosk}

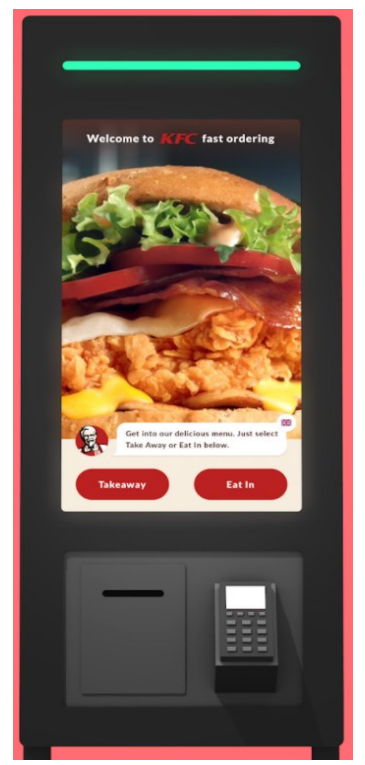

Fig. 1. KFC Kiosk [22].

The KFC kiosk is foreseen to get order more quickly from customers as it is rolled out across restaurants in Poland.[22] Advantages are related to faster order, eye catching, increased productivity. Disadvantages are that if they do not work properly, clients will go to competitors. Analysing that we consider that in order to improve this approach, while people are waiting to order, they should have the option to download the app of the device on their smartphones, order on their smartphones and generate a QR code. When it is their turn, they could just scan the code and pay. This is also great because it reduces the risk of infection significantly, as not having the need to touch the screen.

\subsection{Robotic arm}

The first restaurant with automatic serving system was opened in Moscow. The clients no longer interact with the employees which makes it ideal to keep the safety measures during the pandemic. However, many fears that it may put in danger the regular jobs of humans. 


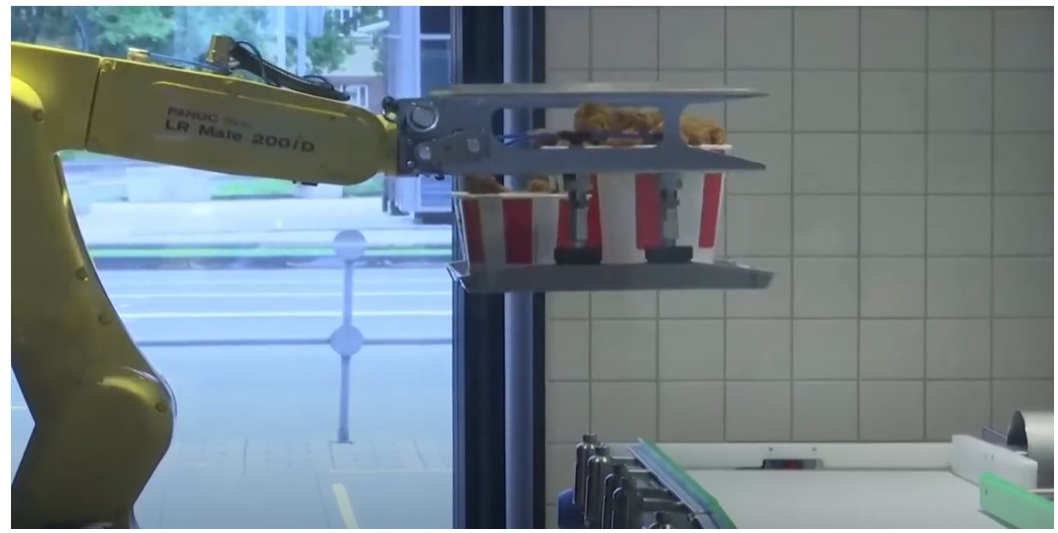

Fig. 2. Robotic arm [23].

A video camera reads the biometric data of the customer then at the pick-up point the system recognizes the customer and his order. A robotic arm places on an automatic band the products, which then are picked up by the customer at the collection point. Advantages: reduces significantly the risk of infection, more efficient. Disadvantages: workflow stops if the robot does not work properly, does not replace the human resource, products are still processed by humans. Analysing that we consider that this model also can definitely be improved, as the robot is quite slow, takes a lot of space and should be fixed on the wall rather than on the ground.

\subsection{Automatic burger restaurant}

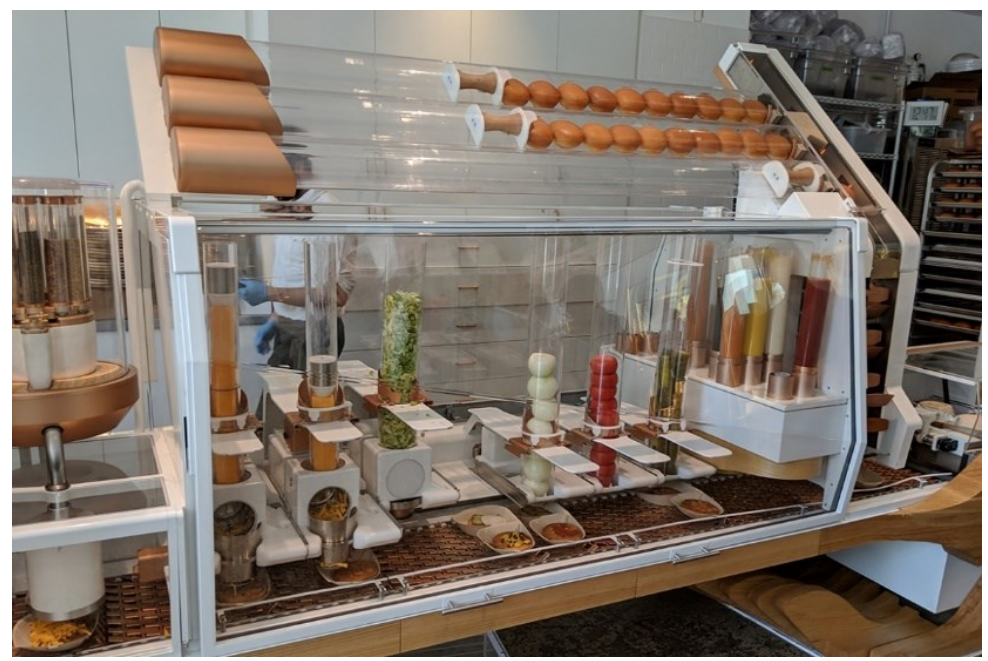

Fig. 3. Creator [24].

Creator claims to automate the preparation of a major food category from start to finish. The main advantage is that it supports an intimate service experience at a reasonable cost. The disadvantages are centred on the need for operators and monitors to load and maintain the machine, and the amount of the investment. Analysing that we consider that as it is a new experience, it may attract more customers, but the costs really need to be addressed, also the process must be more optimized in order to not need so much human resource. 


\section{Introducing a small production line technological model}

We choose to illustrate the use of introducing digital twining in fast food industry using as a case study TASTY FRIES SRL. It is a real fast-food company owned by one of the authors. The young company sells a diversity of foods and sauces both as single items and in form of a menu. In the form of a menu potatoes and wings come with or without soft drinks packed in bags, individually. In the relationship with customers the fast-food company considers simplicity and comfort and pays close attention in task performing while constantly aiming for work efficiently and reduced waste impact by separate waste collection $[25,26]$.

A technological flow was established starting with the customer's order at the working point up to delivery of that order. Next the steps for the technology flow were established for each product as follows:

For French fries:

1. Frozen products delivered by the supplier will be stored in the potato refrigerator.

2. The next step is to check if the equipment is in optimal use parameters and properly sanitized.

3. Filling the vats in the fryers with oil.

4. Starting the fryers at a temperature of $170{ }^{\circ} \mathrm{C}$.

5.After reaching the optimum temperature, the bag of potatoes is opened, and the potatoes are placed in the basket fryer.

6 . The basket of the fryer is inserted in the hot oil.

7. After about 3 minutes, the basket of French fries is taken out of the oil and placed on the frying pan support for oil leakage.

8. The next step is to place them in the heater dedicated to French fries to make them maintain temperature and texture.

9. Then season the potatoes and serve them with the funnel-type scoop in a cornet, over which the other ingredients (topics) are added (sauces, parmesan, cheese, etc.), depending on customer preference.

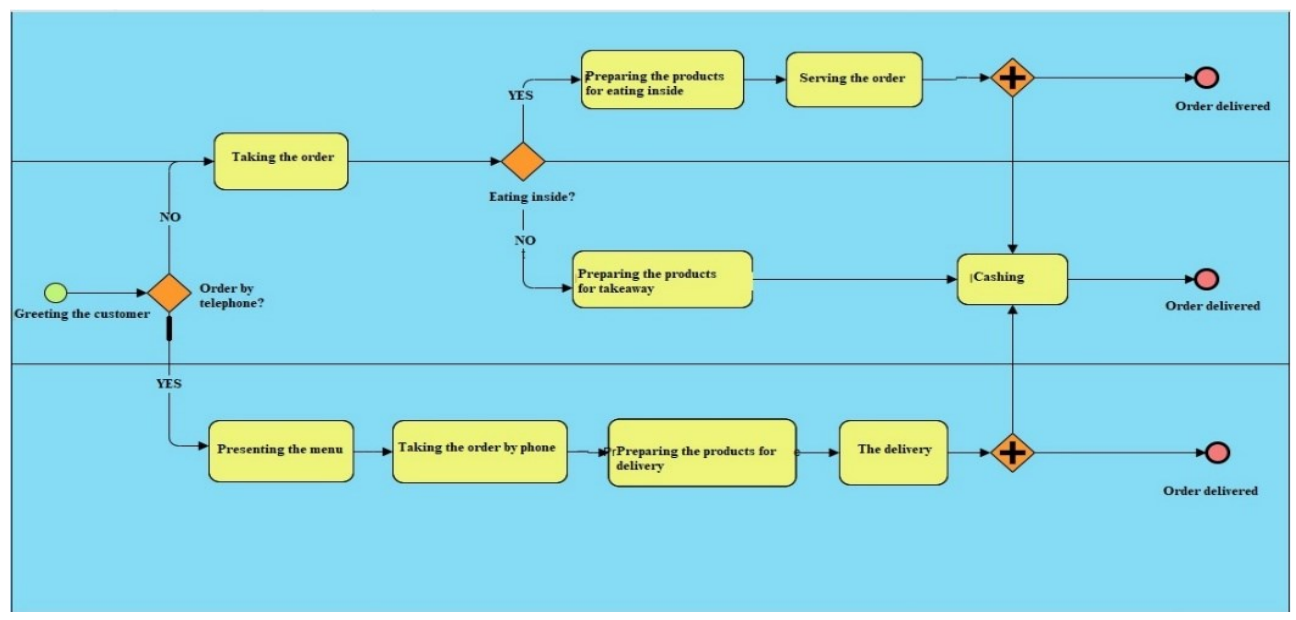

Fig. 4. Technological flow model.

For fried wings:

1. Frozen products delivered by the supplier will be stored in the refrigerator for wings.

2. The next step is to check the equipment if they are in optimal use parameters and properly sanitized.

3. Filling the vats in fryers with oil. 
4. Starting the fryers at a temperature of $170^{\circ} \mathrm{C}$

5.After reaching the optimum temperature, the wing bag is opened, and the wings are placed in the fryer basket.

6. The basket of the fryer is inserted in the hot oil.

7. After about 8 minutes, the basket with the fried wings is removed from the oil and placed on the support fryer for oil drain.

8. The next step is to place them in the heater dedicated to fried wings to make them maintain temperature and texture.

9. Next, season the wings and serve them straight into a cardboard tray or on the menu with potatoes and / or other products.

\section{Using the technological model for generating a processing architecture digital twin}

We focused our case study on the technological flow model of a real start-up enterprise active in fast food industry as presented in Fig. 4. To start with, given the material flow paths it is essential to identify and remove flow concentrators to prevent further material flow blockages. After that we can use the digital twin to evaluate various production scenarios and choose the best solution in terms of productivity.

As a first step we create and simulate the virtual model of the processing architecture corresponding to the technological flow using WITNESS Horizon simulation software.

The models contain elements, such as: refrigerators used for storing raw material goods, fryers, human resources for handling the fryers and for customers interface (taking orders and delivering them), heaters, serving cons, cardboard trays, toppings, spices, supports, conveyor belts for transporting the products from one workstation to the next one up to the destination (the consumer). These structural elements were defined and displayed as a virtual model.

The circulating entities (in our case study represented by potatoes and wings) are restricted to several trajectories in the processing system by some established using rules as: "push ...to....", "pull...from...", "push from...out of world", "push...to ship" interconnecting various structural elements.

As entry data necessary for the virtual prototype to simulate the real system exploitation behaviour, we used the processing times given by the fast-food company`s administrator.

Table 1. Processing times.

\begin{tabular}{|c|c|}
\hline Elements & $\begin{array}{c}\text { Manufacturing } \\
\text { times [min] }\end{array}$ \\
\hline Potatoes & 4 \\
\hline Chicken wings & 4 \\
\hline Fryer_1 & 3 \\
\hline Fryer_2 & 8 \\
\hline Potatoes_work_station & 0.5 \\
\hline Wings_work_station & 0.5 \\
\hline
\end{tabular}


Processing times are the main influence on productivity rates. Because we are dealing with a finite simulation, we must establish the simulated time interval before being able to run the actual material flow simulation. The company works for twelve hours per day, thus we run the simulation for one working day.

The digital twin has the possibility to monitor the productivity using the element ("count") to quantify the number of portions (potatoes and wings) that were served during a workday. At the end of the day activity reports are generated for the structural elements. Based on these reports one can diagnose the processing system productivity issues.

\section{Material flow simulation and results}

The virtual model of the production line is based on the material flow management algorithms used in various industrial applications for digital twining [27 - 30]. Based on the technological flow model and the structural elements presented above we created a digital twin of the preliminary manufacturing architecture model using as a flow simulator WITNESS Horizon software. The following structural elements were defined:

$>2$ human resources (Worker_1, Worker_2);

$>2$ refrigerators (named Refrigerator_1, Refrigerator_2);

$>2$ fryers (Fryer_1, Fryer_2)

$>2$ heating stations (Heating_station_1, Heating_station_2)

$>2$ workstations (Potatoes_work_station, Wings_work_station)

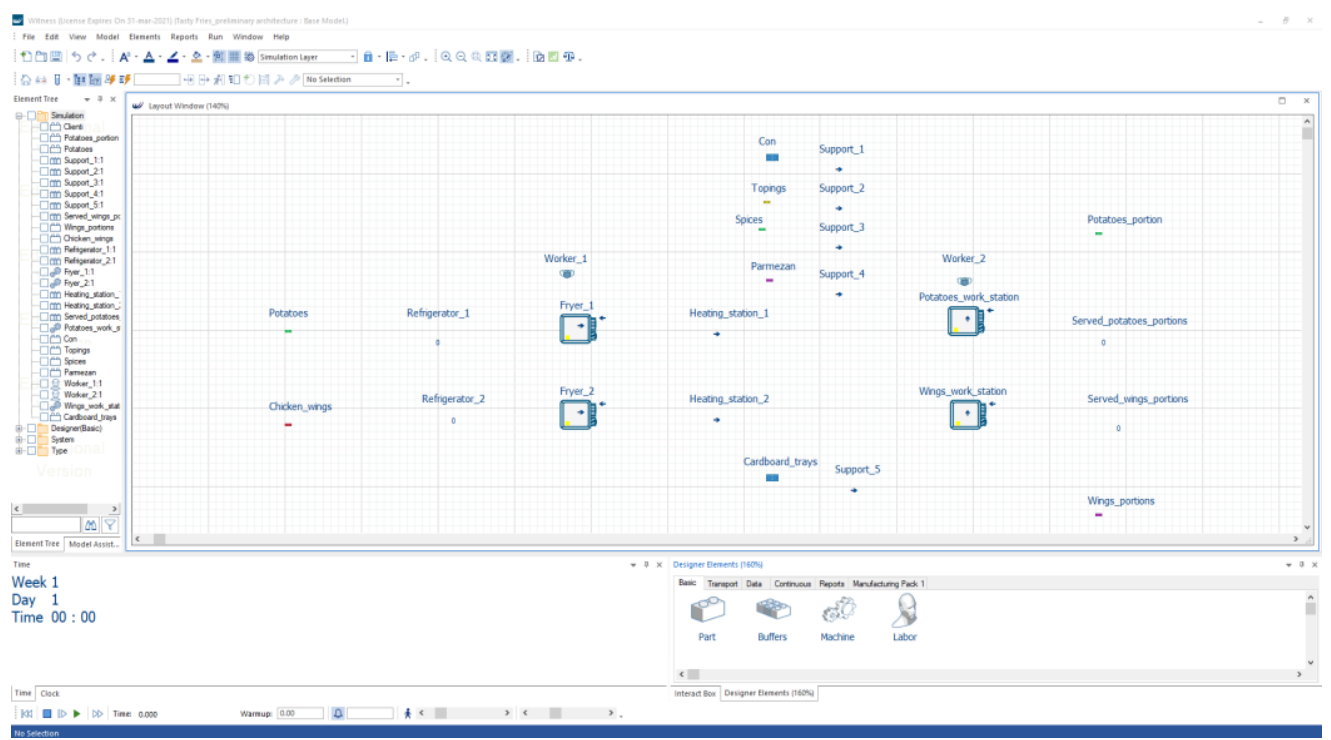

Fig. 5. Digital twin of the preliminary architecture. 


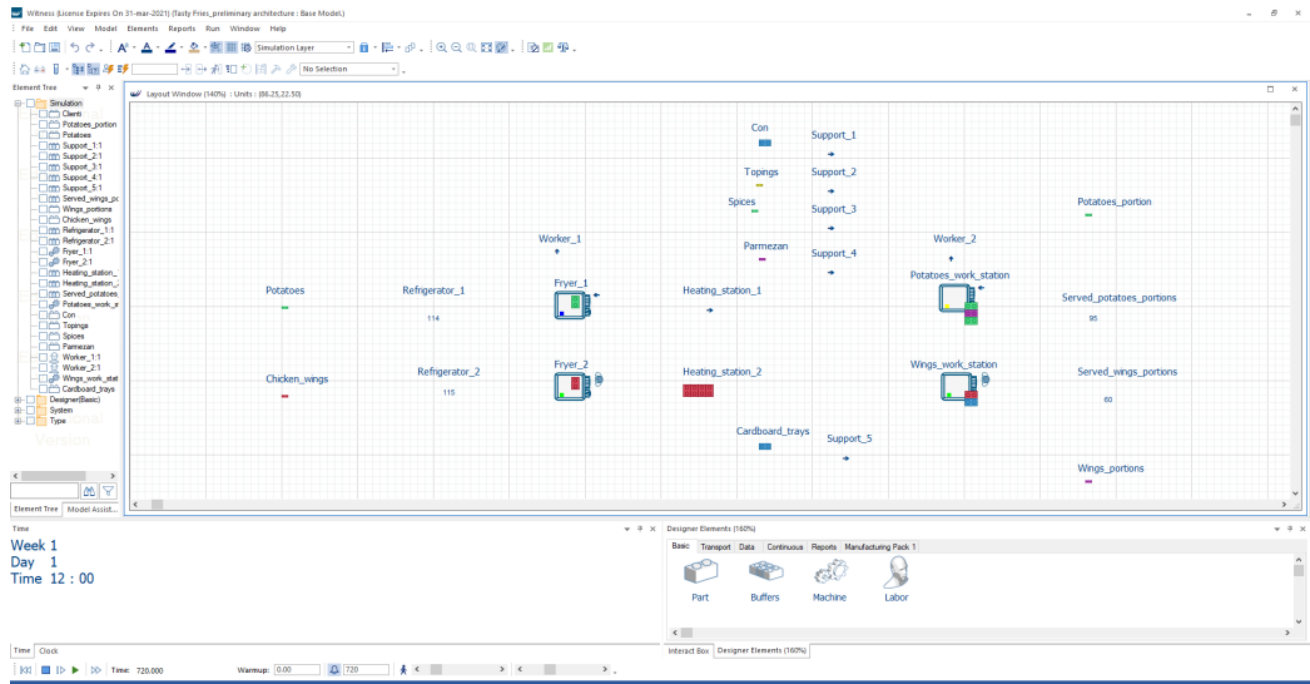

Fig. 6. Virtual model diagnosis results after simulation.

After the simulation time passed (Figure 6, Figure 7) we learned the fast-food company has the capacity to prepare 95 portions of potatoes and 60 portions of wings.

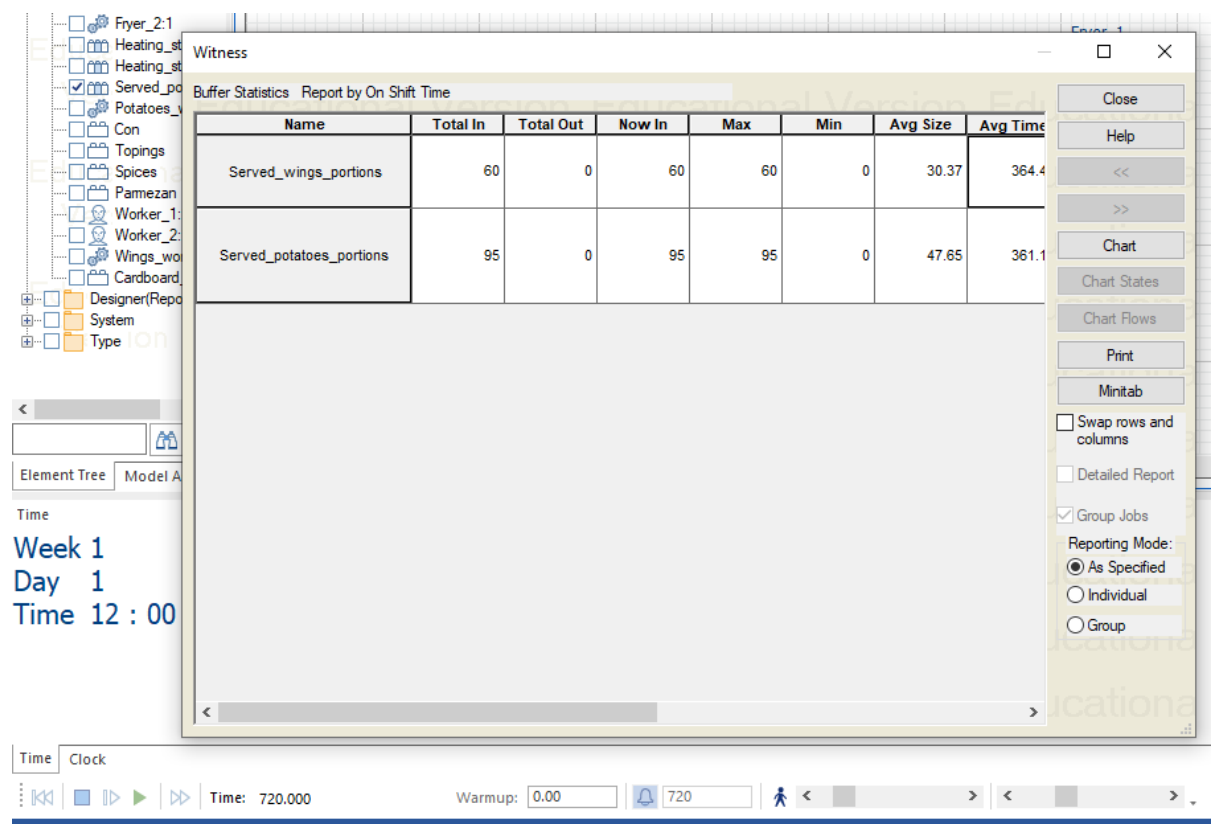

Fig. 7. Activity report for the total amount of portions to sell.

In the same manner several reports (meant to diagnose the system productivity behaviour) were generated for the entire preliminary model. 


Fryer_1_Chart
\begin{tabular}{|l|r|r|}
\hline Waiting Parts & $0 \%$ & 0.14 \\
\hline Busy & $28 \%$ & 27.50 \\
Blocked & $0 \%$ & 0.00 \\
\hline Setup & $0 \%$ & 0.00 \\
Broken Down & $0 \%$ & 0.00 \\
Wait Cycle Labor & $72 \%$ & 72.36 \\
Wait Setup Labor & $0 \%$ & 0.00 \\
Wait Repair Labor & $0 \%$ & 0.00 \\
\hline
\end{tabular}

Fryer_2_Chart

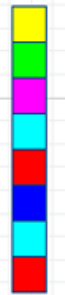

Waiting Parts

Busy

Blocked

Setup

Broken Down

Wait Cycle Labor

Wait Setup Labor

Wait Repair Labor

\begin{tabular}{|r|r|}
\hline & \\
\hline $0 \%$ & 0.00 \\
\hline $73 \%$ & 72.50 \\
$0 \%$ & 0.00 \\
$0 \%$ & 0.00 \\
$0 \%$ & 0.00 \\
\hline $28 \%$ & 27.50 \\
$0 \%$ & 0.00 \\
$0 \%$ & 0.00
\end{tabular}

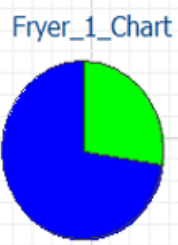

Fryer_2_Chart

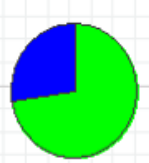

Fig. 8. Activity reports for Fryer_1 and Fryer_2.

In figure 8 we detail the parameters for each of the two fryers which are the most important elements in this process. It looks like those elements are not working at $100 \%$ due to the lack of the worker's presence. This is an issue that should be addressed during the optimisation process.

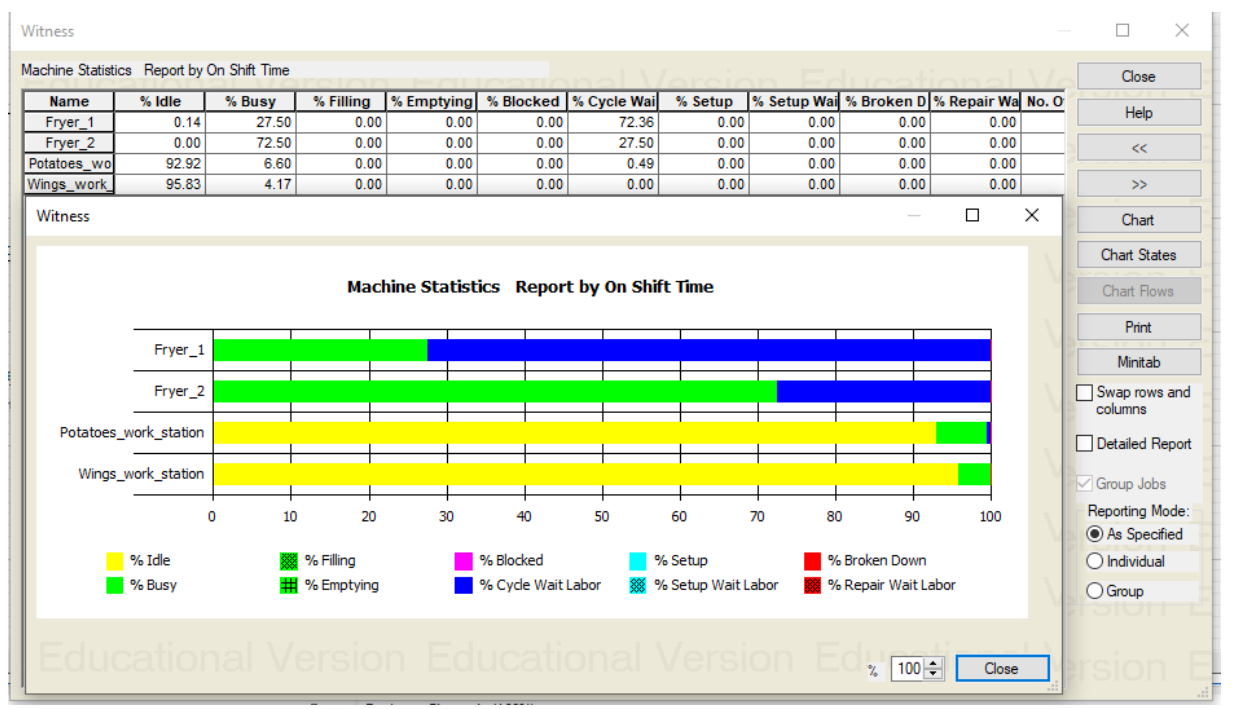

Fig. 9. Activity reports for all work points.

Analysing the activity reports for the workstations (Figure 9) one can notice that "Potatoes_work_station" and "Wings_work_station" have over 90\% wait time. This issue should also be addressed during the optimisation process. The same situation can be addressed to Worker_2; it`s idle time being over $80 \%$ of the total working time. 


\section{Material flow optimisation methods}

After the material flow simulation is completed, we can start the optimisation process. There are two methods which can be used in this situation.

Firstly, we can try a functional remodelling of the architecture that consists in changing parameters, the processes orders, etc. Basically, we are remodelling the system by keeping the same components. We have decided to use both workers on Fryer_1 and Fryer_2 as opposed to just one as in the preliminary simulation.

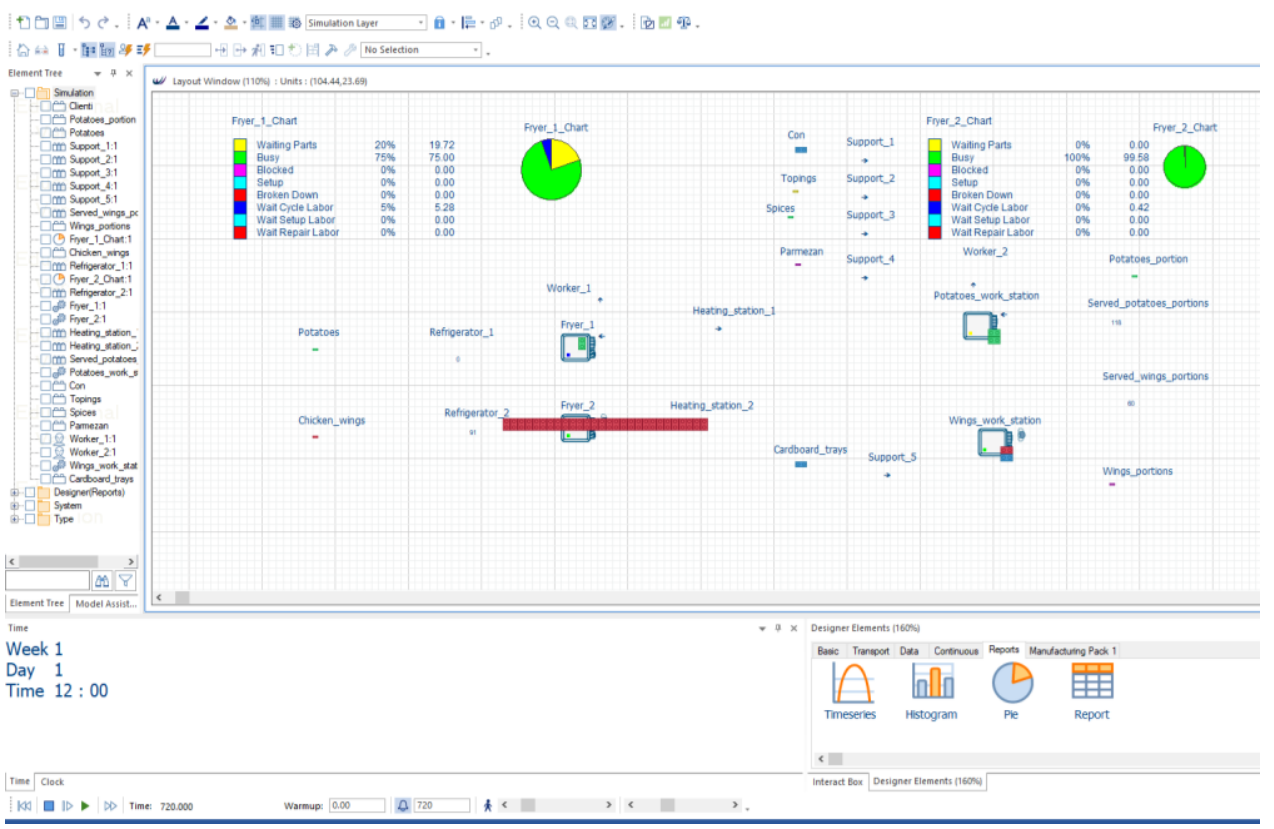

Fig. 10. Virtual model diagnosis results after simulation of functional remodelling.

After simulating the functional remodelled architecture (Figure 10, Figure 11) we increased the fast-food company capacity to prepare 118 portions of potatoes. We have managed to improve the working times of the two fryers. Fryer_1 now has a working time of 75\% and Fryer_2-99.58\%. 


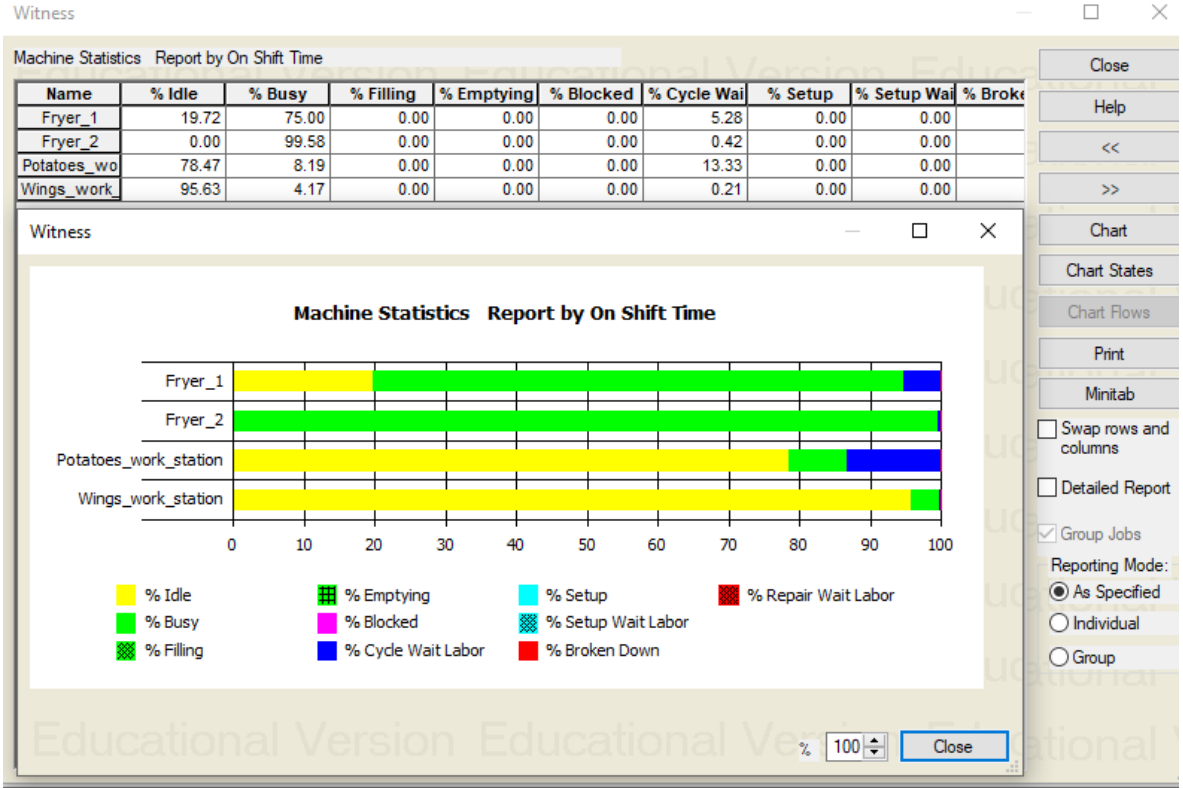

Fig. 11. Activity reports for all work points after functional remodelling.

The results obtained from this first optimisation can be further improved. To do so we will continue with the second method of optimisation: technological remodelling. When rebuilding the system, through this method we will reconsider the whole system. This type of remodelling allows us to add or remove elements, as necessary.

After several remodelling attempts, we obtain the best system version (Figure 12) by adding a second Fryer_2 and a third human resource. This optimisation method resulted in a productivity increase of $1.1 \%$ as well as an improvement for the work points busy times.
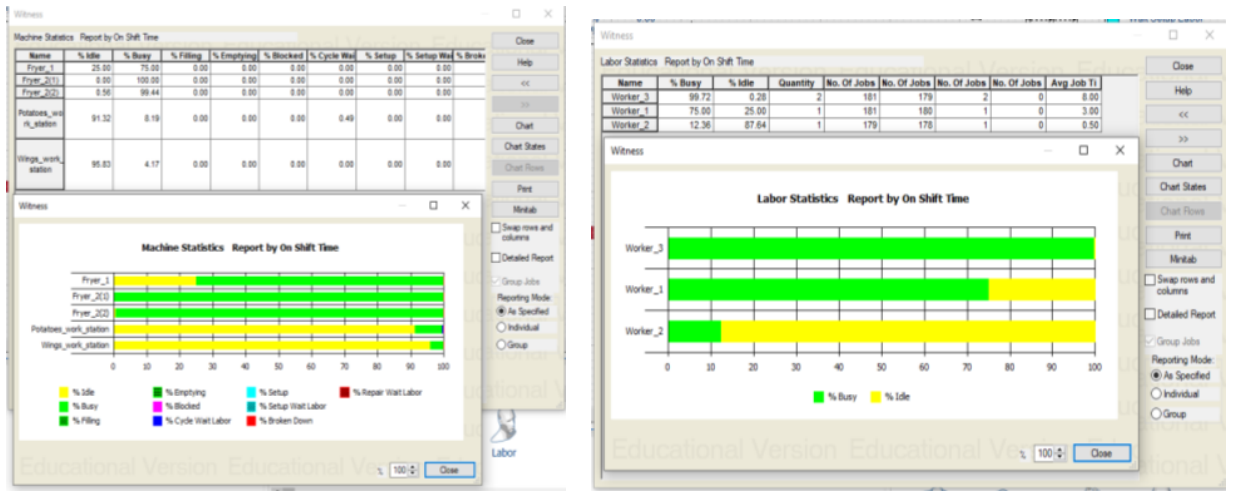

Fig. 12. Activity reports for all work points and human resources after technological remodelling.

When conducting a technological remodelling is always best to do an economical analyse to see if the investment can be deducted from the productivity increase. 


\section{Conclusion \& further intensions}

The design of the virtual prototype of the production line described here is based on an Industry 4.0 approach extended to a processing facility. This is a heterogeneous process, based on the analysis of technical processes, reference processing architectures and simulation techniques. The main research results presented here focus on modelling and simulating the digital twin on the processing architecture, integrating device connection and data processing in material flow management. The aim of this paper is not only to implement an automated production line in an existing fast-food company that in the present moment functions just on human resources but to use a digital twin of the production line to optimize its architecture and to evaluate various production scenarios. The accent is put on exploring different possibilities to increase productivity and profit in fast food production architectures using an approach based on virtual modelling and simulation.

To illustrate the purpose of the digital twin using a study case a technological flow was established for each of the two products that are offered by a real company to the consumers. Based on the technological flow and other information received from the company's administrator we designed a digital twin of the preliminary architecture using WITNES Horizon for the virtual model. After performing various simulation using this model, we were able to analyse the system 's performance as well as the behaviour of each of the model's components. This diagnose helped us to obtain important information regarding the optimisation process identifying and eliminating the material flow concentrators in order to increase productivity. Some significant future developments will be structured on specific applications of digital twining in improving the evaluation of various production scenarios. Also integrating fast food industry in a smart city environment via an automated waste collection system is a top priority of our future research.

\section{References}

1. J. Reis, G. Goncalves. IECON 2017 - 43rd Annual Conference of the IEEE Industrial Electronics Society, 3396 (2017)

2. H. Hirsch-Kreinsen, J. Labour Market Res 49,1 (2016)

3. T. Mazali, Springer-Verlag London Ltd., part of Springer Nature 2017, Vol.:(0123456789)1 3AI \& SOCIETY 33:405 (2018)

4. M. Guran C.E. Coteţ, C.L. Popa. Journal of Proceedings of the International conference on manufacturing systems ICMAS 2009, Bucharest, Romania, 4, (2009)

5. M.E Porter0, J.E. Heppelmann. Harvard Business Review, October 2015, 1 (2015)

6. M.E Porter0, J.E. Heppelmann. Harvard Business Review, November 2014, 1 (2014)

7. Y. Laili, S. Li \& D.Tang. Robotics and Computer-Integrated Manufacturing, 61, (2019)

8. Leng, J., \& Jiang, P. Journal of Intelligent Manufacturing, 30(3), 979 (2020)

9. Y. Liu, L. Wang, X.V. Wang, X. Xu., \& L. Zhang. International Journal of Production Research, 57(15-16), 4854 (2019)

10. W. Zhang, W., Ding, J., Wang, Y., Zhang, S., \& Xiong, Z. Journal of Manufacturing Systems, 53, 249 (2019)

11. D. Berthelot, C. Raffel, A. Roy, I. Goodfellow. International Conference on Learning Representations. (2019)

12. T. H. Kim, M.Wimble \& V. Sambamurthy. European Journal of Information Systems, 27, 449 (2018)

13. B.Hong, L. Kueng \& M. Yang. Management Science, 65, 5152 (2019)

14. M. Fleischmann, K. Kloos, M. Nouri \& R. Pibernik. European Journal of Operational Research, 286, 250 (2020)

15. T. Qu, S.P. Lei, Z. Z. Wang, D. X. Nie, X. Chen, \& G. Q. Huang. The International Journal of Advanced Manufacturing Technology, 84, 147 (2016) 
16. G. Dragoi, A. Draghici, S.M. Rosu, C.E. Cotet, L. Ivascu. International Conference on Enterprise Information Systems, Vilamoura, PORTUGAL Date: OCT 05-07, 2011. ENTERPRISE INFORMATION SYSTEMS, Communications in Computer and Information Science, 219, part 5, 410 (2011)

17. G. Dragoi G. C.E. Cotet, L. Rosu, S.M. Rosu, The Journal of Mechanical Engineering 7-8, 526 (2006)

18. McKinsey, Industry 4.0. How to navigate the digitization of the manufacturing sector. Berlin, Düsseldorf, and Munich: McKinsey, (2015)

19. V.Villani, F.Pini, F. Leali, C.Secchi. Mechatronics, (2018)

20. G. Michalos, S. Makris, P. Tsarouchi, T. Guasch, D. Kontovrakis, and G. Chryssolouris. Procedia CIRP, 37, 248 (2015)

21. L.Wang, R. Gao, J. Váncza, J. Krüger, X.V.Wang, S. Makris, G.Chryssolouris, CIRP Ann. DOI:10.1016/j.cirp. (2019)

22. P. Tsarouchi, G. Michalos, S. Makris, T. Athanasatos, Dimoulas, K. and Chryssolouris, G. International Journal of Computer Integrated Manufacturing, 30(12), 1272 (2017)

23. https://ribot.co.uk/work/kfc-kiosk

24. https://www.youtube.com/watch? $\mathrm{v}=\mathrm{CB} 2 \mathrm{NwTN} 513 \mathrm{M} \& \mathrm{t}=9 \mathrm{~s}$

25. https://hackaday.com/2018/10/11/i-ate-a-robot-hamburger-before-the-restaurant-wentout-of-business/

26. C.L. Popa, Carutasu, G., C.E Coteț, N.L. Carutasu, T. Dobrescu. Sustainability, 9, issue 11, 2064, (2017)

27. C.E Coteț, G.C. Deac, N.C. Deac, C.L. Popa. Sustainability 12(5), 1839 (2020)

28. C.E Coteț, C.L. Popa, Enciu G., A. Popescu, T. Dobrescu, Int. J. Simul. Model, 15, number 1, 5, (2016)

29. C.L. Popa, C.E Coteț, D. Popescu, M. Solea, S.G. Şaşcîm (Dumitrescu), T. Dobrescu. WASTE MANAGEMENT \& RESEARCH, 36, Issue:7, 653 (2018)

30. D. Popescu, D. Anania, C.E Coteț, C. Amza, Int. J.Simul. Model 12, vol. 2, 82 (2013)

31. C.L. Popa, C. E Cotet, V. Ionita and S. Gavrila. Procedia Engineering 100, 334 (2015) 